contents of the flowing river. One old woman, however, dispelled the Templar's idea by stating that she had felt the smell of 'brumstane' near her dwelling, and on searching the premises it was found the water-barrel had got a saffron cap on, and was otherwise dusted with the subtle, powder. As this mystery, if it is not explained, may prove serious to the nervous, superstitious, or credulous part of the community we may as well add that at this season districts in the neighbourbood of fir plantations run the risk of a thorough dusting of this powder if there is the slightest breeze, as the cones of the young Scots fir are thickly coated with yellow powder or pollen, which will give out a blinding saffron cloud on the slightest irritation."

The laudable desire of our newspaper correspondent to relieve the anxieties of his neighbours at a time when the Presbyterian world is much exercised over the question of eternal and sulphureous punishment, can be fully appreciated only by natives. But in my opinion, the correspondent, in his clear knowledge of the nature of the "brimstone" deposit, exhibits a most praiseworthy tendency to explain the natural in terms of the natural; whilst the incident tends to show at the same time that there are not a few persons in this world to whom a course of elementary studies in natural history would serve as a means of culture, not to say of common protection against ludicrous mistakes such as those against which $\mathrm{Mr}$. Carpenter inveighs. ANDREW WILSON

Edinburgh Medical School

\section{Plague of Rats}

I ser by Nature, vol. xx. p. 65, that Mr. Orville A. Derby contributes some very interesting information relating to a plague of rats in Brazil, and adding that the plague "is said to occur at intervals of about thirty years, and to be simultaneous with the drying of the Taquara, or bamboo, which everywhere abounds in the Brazilian forests." It may be interesting to know that a similar plague of rats visited the higher coffee districts of Ceylon during the year 1875 , doing great damage to young and old plantations alike.

It is remarkable that the invasion of rats was simultaneous with the flowering and death of the Nilloo (Strobilanthes), which forms the greater part of the underwood of Ceylon forests, and is said to flower and die once every seven years. The most remarkable part of the plagte was that the rats did not seem to devour any part of the branches they cut ofi, but to nip off and leave them untouched upon the ground. So serious indeed was the damage done, that on some coffee estates rewards were given to coolies for every rat they caught, and it was not an uncommon thing to hear of three or four hundred rats being destroyed, on one estate only, per week.

Between the years 1840 and 1850 there was a similar plague in the Kalebokka coffee district, where the damage done was immense, but I an not aware if it was so general as in the rat plague of 1875 . It is to be hoped that we may not again be invaded in 1882 , when the Nilloo is next expected to die.

Ballangoda, Ceylon, June 16

FREDERICK LEWIS

\section{Glow-worms}

SHELLEY sings of a "glow-worm golden in a dell of dew," but last night, at 1o o'clock, while travelling on a bridle path amcng the bleak lonely mountains of Tynron, Dumfriesshire, bearing up against a high wind with cold rain, I espied three glow-worms shining among the grass and ferns. I had seen them in the same locality before, but scarcely expected to have noticed them in such ungenial weather when summer has with us scarcely yet begun. July 8

J. S.

\section{Headless Butterfly laying Eggs}

Anour three o'clock on the 11 th inst. I picked up a butterfly, probably belonging to the genus Vanessa. It was a female, the head of which had recently been plucked off by a bird, and was lying near the body. 'Thiuking it was dead, I carried it home to examine the wing scales. On clipping off a bit of wing about four hours afterwards, the legs moved, and in a short time an egg was laid. In about two minutes another egg was laid. Others followed, till five-and-twenty had been expelled. Tremors of the legs and wings accompanied each deposit. The laying ceased, and the headless mother seemed dexd. Next morning, on touching her, the motions of the less and wings were repeated, and in a short time the laying was resumed. On close examination a heaving of the wings and rings of the abdomen could be observed, with about the frequency of human breathing. At the end of twenty-nine and a half hours from the time of finding, the laying ceased; seventy-eight eggs were laid by the butterfly with her head off.

North Kinmundy, Aberdeen, July 14

A. STEPHEN WILSON

\section{THE COMPARATIVE ANATOMY OF MAN}

III.

The Mongoloid People of Asia

TO the north and east of the line already spoken of, running northwards from the head of the Bay of Bengal to the north of the Caspian Sea, the bulk of the people of the Continent of Asia belong to the Mongolian, or better, Mongoloid type.

The physical characters of these people, best seen in the so-called Tartars who inhabit the country to the north of the great wall of China, are as follows: the complexion is pale brown, usually with a yellowish tinge; hence they are spoken of as the "yellow races," in contradistinction to the (50-called) white and black races. Their hair is black; perfectly straight, and coarse. In microscopic section it is seen to be of large size, and more inclining to cylindrical than in other races, but it varies much. Except on the scalp, where the hair is often long, the capillary development is very scanty. On the face it is often limited to two slender pencils on the upper lip; and the beard, when developed, is acquired comparatively late in life. The face is broad and flat; the space between the eyes is wide; the nose small, straight, and compressed; the eyes dark and small; the aperture between the lids narrow and somewhat oblique, being raised at the outer corner ; the upper lid drooping, the inner corner partly covered by a vertical crescentic fold of skin; the cheeks very prominent; the mouth and lips of moderate size, the lower lip often hanging; the chin small and sharp.

The osteological characters of the typical Mongolian are more marked in the face than in the cranium, for the latter may vary between the extremes, of brachycephaly and dolichocephaly, though the former prevails. The face is large, being both high and broad; the forehead flat, the glabella and superorbital ridges slightly developed; the orbits round, with thin sharp margins, the sub-glabellar nasal depression very slight; the nasal bones narrow and flat; the whole framework of the nose inclining to the leptorhine form; the jaws of medium prominence; the arch of the mouth broad and round; the malar bones both broad and deep. Perhaps the most distinctive feature of the Mongoloid face, which gives it the characteristic appearance, is the forward position of the outer margin of the orbit, as compared with the median line of the face. In order to estimate this character with exactness, Prof. Flower measures the angle formed between two horizontal lines meeting at the most depressed point of the nasal bones in the middle line (the apex of the angle) and resting on the middle of the outer margins of the orbit. This nasi-malar angle gives valuable average results. For instance, the average of I 30 European skulls is I3I deg., of the twenty Maravars mentioned in the last abstract, exactly the same; of 20 African negroes I 34 deg., and of 20 Australians $135 \mathrm{deg}$. In all of the true Mongolian races, the average exceeds 140 deg. Thus, in 4 Samoyedes it is 144 deg. ; in 16 Chinese, 142 deg.; in 7 Japanese, 14I deg. ; in 4 Burmese, I 44 deg.; in 26 Eskimo, 144 deg.

The Mongoloid races of Asia are conveniently divided into two groups, the northern and the southern. The former, called Mongolo-Altaic races, are united by languages having considerable affinities. They nearly all lead a nomadic life, clepending for their living on bunting, fish-

$x$ Abstract of Prof. Flower's Hunterian Lectures, delivered at the Roya College of Surgeons, commencing on Wednesday, March 5. Continued from p. 246. 
ing, and cattle-breeding. Occasionally, when united under the leadership of some military chieftains of extraordinary capacity, as Attila, Tchinghis Khan, and Timur, they have overrun nearly the whole of the continents of Asia and Europe; now, however, they are everywhere either the actual subjects, or live by sufferance, of the people over whom they formerly terrorisedthe Russians, Chinese, \&c.

The anatomy of these races is only represented in the museum by a complete skeleton and several skulls of Samoyedes, a people now inhabiting the most inclement parts of North-western Siberia. They were conquered by the Russians in 1499. They are dwellers in tents made of pieces of bark covered with reindeer skins, and live chiefly by fishing and the chase, and by the produce of the herds of reindeer which they keep. Their external physical characters are always described as being typically Mongolian. Their skulls are very broad and low, the average latitudinal index of four being 847 , and the average altitudinal index 719. They are, therefore, decidedly brachycephalic. The orbits are round (megaseme), the average index being 938 ; the nasal index is 431 , so that they are truly leptorhine; the alveolar index of IO2 shows them to be mesognathous, with a strong inclination to prognathism. The skeleton, that of an old male, is slightly below five feet in height. The pelvic index is only 78 , but both bones of the upper extremity are disproportionately long compared with those of the lower limb, and the radius and the tibia are relatively longer compared with the proximal segments of the limbs than in Europeans.

The Turks, the Magyars, the Finns, and other representatives of the Mongolian type, have for so many generations intermingled with the people through whom they have passed in their migrations, that their original physical characters have been completely modified. Even the Lapps, a diminutive race of nomads, inhabiting the most northern parts of Europe, supposed to be of Mongolian descent, show so little of the special attributes of that race, that it is difficult to assign them a place in a classification based on physical characters. Their crania are remarkably capacious, one in the collection being as large as 1,800 c.c., and another 1,600 . They are brachycephalic, have a latitudinal index (average of seven) of 812. The orbital index of the same number is 984 . The nasi-malar index, though lower than in the true Mongolian, being about $136^{\circ}$, is higher than in the other Europeans.

\section{Races of Eastern Asia}

Many races of Asia, of similar physical type to the Mongolian, are divided from the Altaic group by language and by mode of life. One large group is formed by the people of Thibet and Burmah, with various tribes dwelling within the north-eastern frontiers of India. The four Burmese crania in the museum are all short, high, round, or rather square skulls; the average latitudinal index is 82 , and the altitudinal index nearly as high. The orbital, nasal, and alveolar indices are all moderate. The nasi-malar angle of $144^{\circ}$ is thoroughly Mongoloid. From the Burmese, the transition (physically) to the Malays is very easy; and through the Malays, the purer races of the Polynesians are connected with the inhabitants of Central Asia.

The various races constituting the population of the vast empire of China all belong to the Mongolian type, and have gradually moved southwards to their present dwelling-places. The existing reigning dynasty is Mandschurian, belonging to the Tungus branch of the Altaics. The Chinese proper formed their earliest settlements in the north-western provinces of what is now called China about 2000 B.C. The aboriginal tribes they found there still exist, as the Miaw or Miautze, \&c.

The following cranial characters of the Chinese are deduced from sixteen specimens of the male sex:-The average capacity is 1,424 . The index of breadth is 782 , so they fall under the mesocephalic category, inclining to brachycephaly. All the other Mongolian races hitherto treated of have been decidedly brachycephalic. The height-index is lower, viz., 753. The general form of the face is Mongolian, the forehead smooth, with little development of the glabella, the space between the orbits wide, the malar bones large and prominent, the anterior root of the jugal arch stands out laterally from the face, then turns sharply backwards beyond the maxillo-jugal suture, instead of gradually sloping backwards from that point, as in the English skull. The nasi-malar angle is 142 deg. The orbital, nasal, and alveolar indices are all medium, being respectively 869,504 , and 993 .

The Japanese differ entirely from the Chinese, and resemble the Altaic races in the polysyllabic character of their language. They appear to have migrated from the Asiatic continent to the islands they now inhabit in the seventh century. B.C., first taking possession of the southernmost island, Kiu-siu, and soon afterwards passing on to Niphon, gradually driving out the original population, the Ainos. It is, however, probable, that some por tion of the latter became absorbed into the conquering race, which circumstance may account for part of the diversity of features and type seen among them. In the main the physical characters of the Japanese are Mongolian. At present we have really very little information about their anatomy. There are but six male skulls in the College Museum, which give the following averages:- $\mathrm{Ca}$ pacity, $\mathrm{I}, 486$; latitudinal index, $77 \mathrm{I}$; altitudinal index, 753 ; orbital index, 910 ; nasal, 472; alveolar, 97I ; nasimalar angle, i4r deg.

The people who inhabited Japan before the Japanese are called the Ainos. They have lately attracted much attention from ethnologists, owing to the fact that in their physical characters, manners, and customs, they entirely differ from all the other races of the part of the world in in which they dwell. They formerly inhabited the whole of the Japanese islands, Saghalien, and the Kuriles. They are mentioned in Chinese books before the time of Confucius, under the significant title of the villous or hairy men, and are called by the Japanese, "Mo-sins," a word having the same signification. "Aino," in their own language, means "the men," or "the people." Their numbers are now extremely reduced, and the territory they occupy limited by the encroachments of the Japanese from the south, who have driven them up to the most northern part of the island of Jesso, while the Mandschu Tartars have taken from them more than twothirds of the Island of Saghalien. "Though their language has received a considerable infusion of Japanese and Mandschu words, it appears to be of fundamentally different origin. They have no agriculture, and live principally by fishing and hunting, shooting deer and bears with the bow and arrow. They appear to be goodnatured, honest, and of a mild, contented disposition.

In stature they are short (the men about 5 feet 2 inches in height), but stouter made, and more hardy and muscular, than the Japanese. Their head is large, their colour rather dark; their forehead low, the superciliary ridges prominent, the nose straight, short, and thick, and rounded at the end. The eyes are open, and not oblique like those of the Mongols, and bright, sparkling, and intensely black. What distinguishes them most in external appearance from all the surrounding races is the abundant development of their hair and beard, but this has been much exaggerated; it is black, coarse, straight, and shaggy; that on the head is worn long over the shoulders, and mingles with the beard. The few skulls known are heavy, and have the muscular impressions strongly marked. The average altitudinal index of four in Dr. Barnard Davis's collection is 78 ; of three measured by Prof. Flower, 74.3. These present none of the 
Eeatures characteristic of Mongolian skulls, the facial bones being more European in type, and the nasi-malar angle only $129 \mathrm{deg}$. The affinities of the Ainos are at present a matter for speculation.

\section{The Eskimo}

The original inhabitants of the whole of the New World are light brown, or copper-coloured, have straight black hair, and show, amid considerable diversity in detail in particular regions, a far greater resemblance than can be found in any other portion of the world's surface of equal extent. The Eskimo, inhabiting the most northern portion of the continent, stand, in many respects, apart from the others, and are evidently quite as nearly allied to some of the Asiatic races as they are to the Americans. These people call themselves Inmuit, which signifies nothing more than "the men," or "the people." The word Esquimaux, as it is rendered in French, or Eskimo, in the Danish method of spelling, now usually adopted in this country, was applied to them by a neighbouring tribe of Indians, and is said to mean "eaters of raw flesh." They dwell in various scattered localities near the northern coast of North America and the great adjacent islands, from Behring's Straits to Greenland, and on the north coast of Labrador. Like the MongoloAltaic races of Asia, they lead a nomadic life, modified somewhat by the peculiarities of the surrounding physical conditions, dwelling in tents in summer, and in houses of snow in winter. Agriculture being impossible in such a climate, their only means of subsistence is hunting and fishing. The flesh of seals, cetaceans, and reindeer forms their principal food. In the pursuit of the two former by sea they use boats, which they manage with great dexterity. They train dogs to draw their sledges, but, unlike the Laplanders, do not domesticate the reindeer. They clothe themselves comfortably in dresses of skin, and employ bows, arrows, and harpoons in the chase. In Greenland they have reached a considerable degree of civilisation, but even here, as elsewhere, their numbers seem to be diminishing.

The Eskimo are generally below the middle size; their head is large, their legs short, and their hands and feet small; their complexion is dusky or swarthy. Their hair is black, straight, and coarse, the beard and moustache generally scanty, though sometimes moderately developed. The eyes are small, black, and sparkling; the elevation of the outer end of the aperture and the vertical fold covering the inner canthus, spoken of before as characteristic of the most typical Mongolian races, have often been observed in them. The nose is usually straight and narrow, and more or less sunken between the prominent cheeks. The mouth is large and the lips rather prominent, generally kept somewhat apart. The chin is small and pointed.

The College Museum contains as many as twenty-seven adult skulls of Eskimos, twenty-four of which are in a condition to form reliable measurements. Of these seventeen appear to be those of males and seven of females.

A typical Eskimo skull always presents such marked characters that it can never be mistaken for that of any other of the groups of mankind. It is of very large size, especially in relation to the rather small stature of the people, the average capacity of 17 male crania in the collection being 1,546 c.c. or $94 \% 3$ c. inches. This is almost exactly the same as the average English (of the lowest class), but it exceeds that of 74 modern Italian males by 7 I C.c., and it is above the average of Australian males by as much as $26 \mathrm{r}$ c.c. or 16 c. inches. The large size of the brain of all hyperborean races, Lapps as well as Eskimo, seems not necessarily to be connected with intellectual development, but may have some other explanation not at present quite apparent. The next distinctive character of the Eskimo skull is its great length and narrowness, especially in the upper part. The base is fairly broad, and the mastoid processes are well developed; but, instead of expanding upwards to the parietal region, it narrows, and, towards the median line above, contracts so rapidly that the upper part of the skull has the form of the roof of a house. Measurements of various series of Eskimo skulls give remarkably uniform results as regards the latitudinal index, the average being from $7 \times 2$ to $71 \% 4$, so that it may be considered as perfectly established, that the Eskimo are among the most dolichocephalic of races. The female skulls are somewhat broader than the male. The index of height is somewhat greater than that of breadth, averaging $73 \cdot 5$. The cranial sutures are very simple; and among the specimens examined there is no case of metopism or persistence of the frontal suture, nor is there any case of the squamosal bone meeting the frontal at the pterion.

The whole face is large, both high and broad; the forehead is flat, the glabella little developed; the orbits are round, and the malar bones of great size and very prominent, giving a nasi-malar angle of $144 \mathrm{deg}$. The nasal bones are small and narrow, often coming to a point at their upper ends, and the whole aperture is very long and narrow. The Eskimo are, in fact, the most leptorhine of all races; the average nasal index of the 17 male skulls before spoken of, being only $42^{\prime} 2$, the average of European crania being about 47 , and that of Australians 56. The projection of the jaw is moderate, giving an alveolar index of 100.8 , which brings them into the mesognathous category, with an inclination towards prognathism. The arch formed by the series of teeth is remarkably short, broad, and round. The teeth are small, and generally become worn down to stumps as life advances.

Two out of the three Eskimo skeletons in the Museum possess one more than the usual number of vertebræ, the additional one being interposed between the dorsal and lumbar series, and partaking of the character of both. The brim of the pelvis is remarkably wide transversely, and thus, as also in the limbs, they deviate widely from the negro type : for example, the humero-radial index, which in the Andamanese is as high as 82, in Negroes 79, in Australians 77, and in Europeans 74, does not exceed $7 \mathrm{I}^{\circ} 3$ in either of the three skeletons, the average being $7 \mathrm{I} \cdot \mathrm{I}$.

Dr. Barnard Davis has shown that the special peculiarities of the Eskimo skull are most marked in Greenland; there is also good evidence that the Eskimo have migrated from the west towards the east, and did not reach Greenland, at all events in its southern parts, until the fourteenth century. Their affinities, moreover, as shown by physical characters, are more with the inhabitants of North-Eastern Asia than with the American Indians, and it is not at all improbable that they are derived from the same stock as the Japanese. In this case the peculiarities by which the Eskimo are differentiated from the Asiatic Mongolians cannot have been developed by crossing with other nations, on account of their complete isolation, but must be attributed to those gradual modifications, produced by causes at present little understood, by which most of the striking variations we have met with in the human species have been brought about; modifications more strongly expressed the more completely isolated the race has become, and the further removed from its original centre of distribution.

\section{OUR ASTRONOMICAL COLUMN}

The Dunsink OBSERVAToRy, Dublin.-The third part of "Astronomical Observations and Researches made at Dunsink, the Observatory of Trinity College, Dublin," has been published by Dr. Ball. It contains four papers, the first by the previous director, Dr. Brunnow, presenting a discussion of observations of the 